\title{
ANALISIS MUSIK LAGU “KHINDU DI HATI” DALAM REJUNG BENGKULU SELATAN
}

\author{
Pebrian Tarmizi \\ pebriantarmizi@yahoo.com \\ Pendidikan Guru Sekolah Dasar Fakultas Keguruan dan Ilmu Pendidikan \\ Universitas Bengkulu
}

\begin{abstract}
Abstrak
Tujuan penelitian adalah menemukan dan mendefinisikan Analisis Musik dilihat dari Konteks dalam musik Rejung "Khindu di Hati” kabupaten Bengkulu Selatan. Teori yang digunakan dari Allan P. Merram yaitu tentang penggunaan dan fungsi. Jenis penelitian yang digunakan adalah kualitatif dengan metode deskriptif analisis. Hasil penelitian ditemukan bahwa Birama pada Rejung "Khindu di Hati" adalah 4/4, tekstur pada lagu ini Monopohny dan mempunyai dua bagian lagu yaitu A dan B. Bagian A terdiri dari (a, a'), a adalah antecedens atau kalimat tanya sedangkan a' adalah consequens atau kalimat jawab. Bigian B $(b=b)$. maksud dari b sama dengan $\mathrm{b}$ adalah Pengulangan atau Repetisi.
\end{abstract}

Kata kunci : Rejung, birama.

\section{PENDAHULUAN}

Manusia sebagai mahluk yang berbudaya sekaligus mahluk yang paling sempurna, dengan akal yang dimilikinya manusia berusaha mengusai alam, mencipta, dan dalam perkembanganya dapat melahirkan kebudayaan yang beranekaragam. Pengertian kebudayaan dapt dilhat dari 3 dimensi atau sudut pandang seperti yang diajukan oleh: Koentjaraningrat (1982:14) bahwa: Kebudayaan adalah kaitan antara wujud ide (gagasan), wujud kelakuan (sosial), dan wujud fisik (kebudayaan materi). Jadi, kebudayaan mengandung kaitan antara pemikiran abstrak dengan tata cara bertindak dan bertingkah laku dengan kelakuan itu sendiri yang menghasilkan budaya konkret.

Kebudayaan apabila diartikan seperti di atas, maka bidang kesenian pada hakikatnya adalah unsur kebudayaan yang bersumber pada wujud ide (gagasan), yang cenderung mengarah pada gagasan estetis, gagasan estetis inilah yang mendorong budidaya manusia untuk menciptakan anekaragam kesenian. Seperti yang dikemukakan oleh Kayam (1981:38-39) yaitu:

Seni tidak pernah berdiri lepas dari masyarakat sebagai salah satu bagian yang penting dari kebudayaan kesenian adalah ungkapan kreativitas dari kebudayaan itu sendiri, masyarakat yang menjaga kebudayaan dan kesenian yang mencipta, mengembangkan untuk kemudian menciptakan kebudayaan baru lagi.

Kesenian dalam kehidupan manusia merupakan ciri khas sesuatu daerah di mana dengan berkesenian orang dapt mengenal kebudayaan yang tumbuh dan berkembang sesuai dengan nilai-nilai adat istiadat yang berlaku pada daerah tersebut. Keberagaman kesenian tradisional yang tumbuh dan berkembang disuatu daerah merupakan aset dan kebanggan dari masyarakat pendukungnya serta menjadi ciri khas daerah tempat tumbuh dan berkembangnya kesenian itu.

Kabupaten Bengkulu Selatan berdiri berdasarkan Keputusan Gubernur Militer Daerah Militer Istimewa Sumatera Selatan pada tanggal 8 Maret 1949 Nomor GB/ 27/ 1949, tentang 
pengangkatan Baksir sebagai Bupati Bengkulu Selatan (sebelumnya bernama Kabupaten Manna Kaur 1945- 1948 dan Kabupaten Seluma Manna Kaur 1948-1949). Pada perkembangan selanjutnya dikuatkan dengan Surat Keputusan Presiden RI tanggal 14 November 1956 dengan Undang- Undang Nomor 4 Tahun 1956. Bengkulu Selatan sebelumnya bernama kabupaten Manna Kaur pada tahun 1945-1948 dan Kabupaten Seluma Manna Kaur pada tahun 1948-1949. Pada tahun 2002 Kabupaten Bengkulu selatan mengalami pemekaran wilayah menjadi 3 Kabupaten yaitu: Kabupaten Kaur, Kabupaten Seluma dan Kabupaten Bengkulu Selatan.

Kajian teori yang digunakan merujuk kepada Alan P. Merriam (1964) dalam bukunya The Anthropology of Music. Northwestern University Prees. Menyatakan ada sepuluh fungsi musik diantaranya: fungsi musik sebagai hiburan,Fungsi musik sebagai komunikasi.

\section{METODE}

Jenis penelitian ini adalah penelitian kualitatif, bertujuan untuk menemukan dan mendeskripsikan musik dilihat dari konteks. Moleong (1981:112) menyatakan bahwa penelitian kualitatif adalah penelitian yang menghasilkan data deskriptif maksudnya data berupa kata-kata dan tindakan dari orang-orang dan perilaku yang diamati sebagai data utama. Data kedua berupa data tambahan yang berasal dari studi kepustakaan.

Moleong (1981:2) menyatakan penelitian kualitatif selalu bersifat deskriptif. Artinya data yang dianalisis dan hasil analisisnya berbentuk deskriptif. Fenomena tidak berupa angka-angka atau koefisien tentang hubungan antar variabel. Data yang terkumpul berupa kata-kata atau gambaran.
Berdasarkan pendapat di atas, dapat dijelaskan bahwa penelitian kualitatif yang menghasilkan data deskriptif, aktivitas penelitian yang diperlukan adalah melihat, meninjau, dan menyimpulkan informasi kemudian mengungkapkan serta menggambarkan secara tepat.

\section{PEMBAHASAN}

\section{Kajian Konteks}

Rejung "Khindu di Hati" di ibaratkan sebuh bangunan rumah. Rumah sebelum di bangun tentu mempunyai bahan-bahan matrial dan mempunyai struktur yang jelas. Untuk itu penulis akan membahas Struktur pada lagu "Khindu di Hati" adalah sebagai berikut:

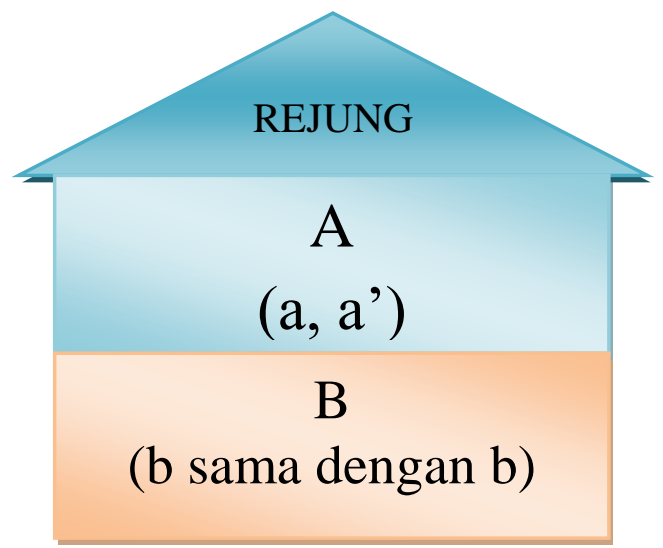

Rejung Khindu di Hati memiliki dua bagian. Bagian pertama kita sebut $\mathbf{A}$ terdiri dari (a, a') a adalah antecedens atau kalimat tanya sedangkan a' adalah consequens atau kalimat jawab. Bigian kedua saya sebut dengan B. maksud dari $b$ sama dengan $b$ adalah Pengulangan atau Repetisi. Birama pada Rejung "Khindu di Hati" adalah 4/4, tekstur pada lagu ini Monopohny dan mempunyai dua bagian lagu yaitu A dan B sepeti yang telah di uraikan di atas tersebut. 
Febrian Tarmizi

Bagian A terdiri dari:

$>\mathbf{a}$

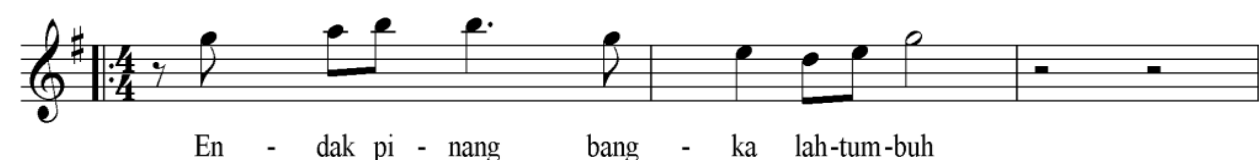

$\mathbf{a}^{\prime}$

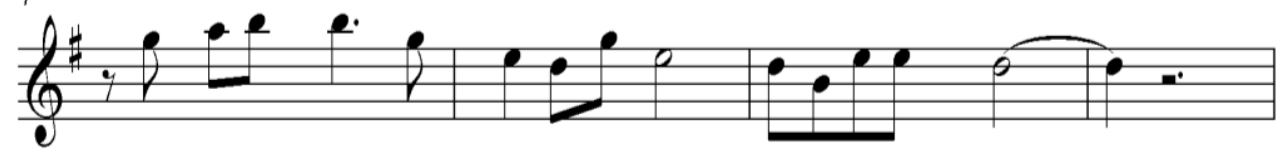

En - dak pi - nang bang - ka lah-tum-buh Tu-tup be-lu - luk

Bagian $\mathbf{B}$ terdiri dari:

$>\mathbf{b}$

8
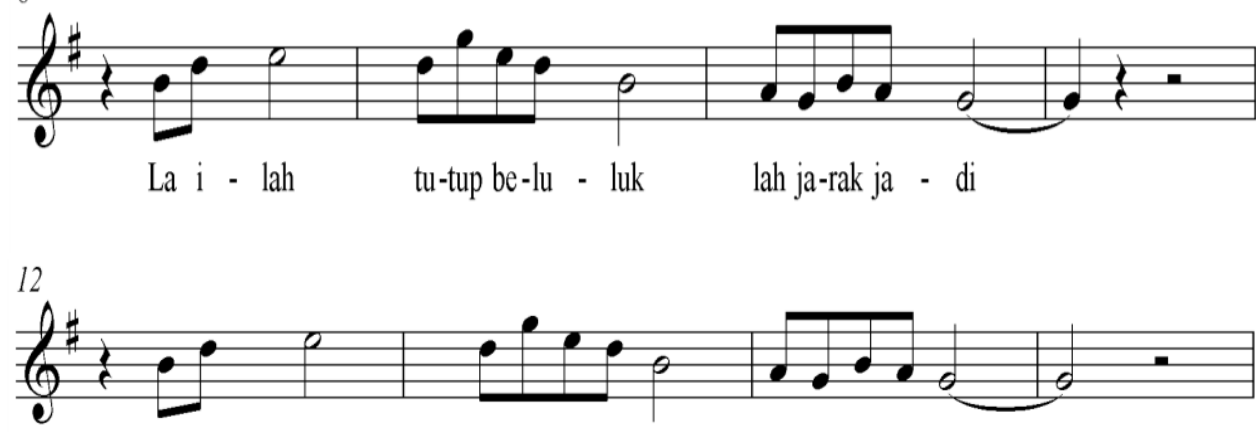

La i - lah tu-tup be-lu-luk lah ja-rak ja-di

Macro Beat bagian A

$\mathbf{a}$

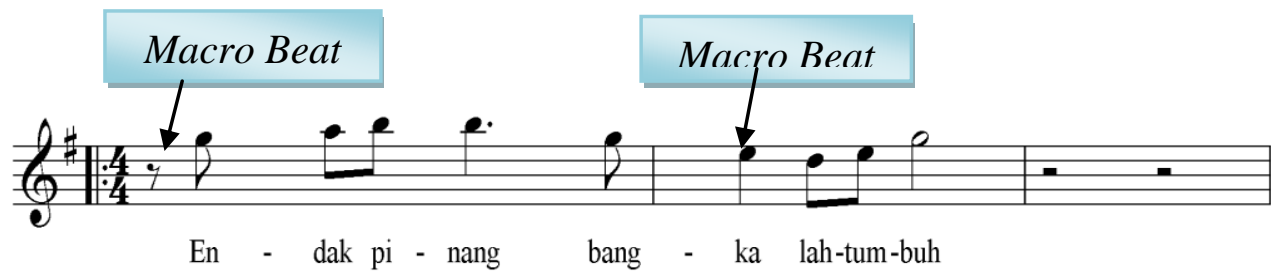

$\mathbf{a}^{\prime}$

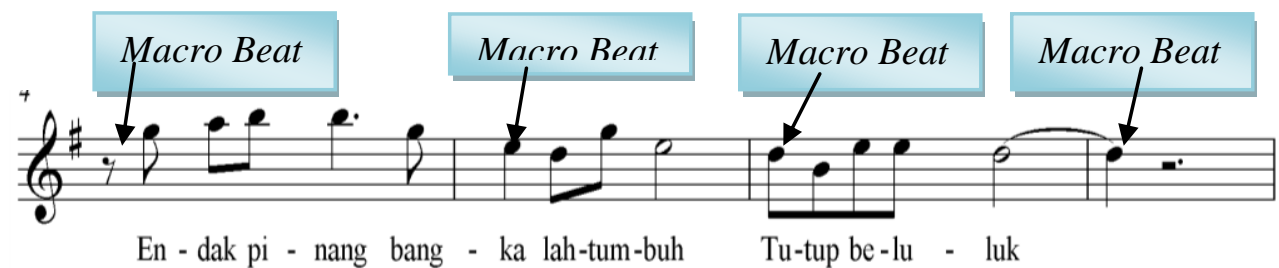




\section{\# $\quad$ Macro Beat bagian B}

b

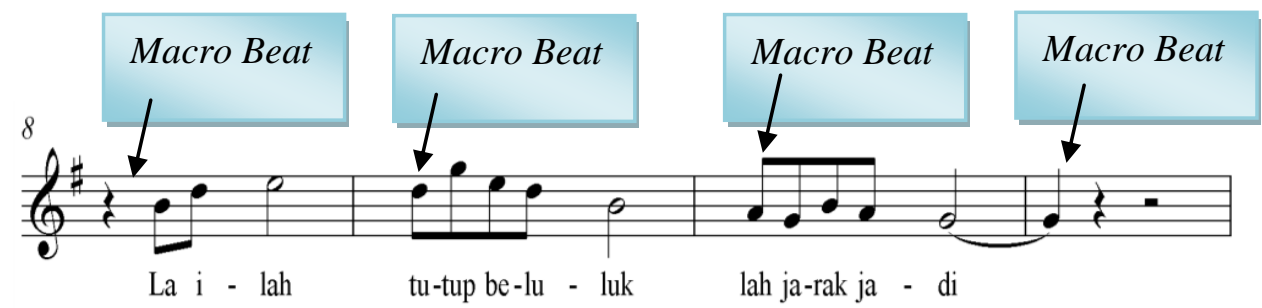

b

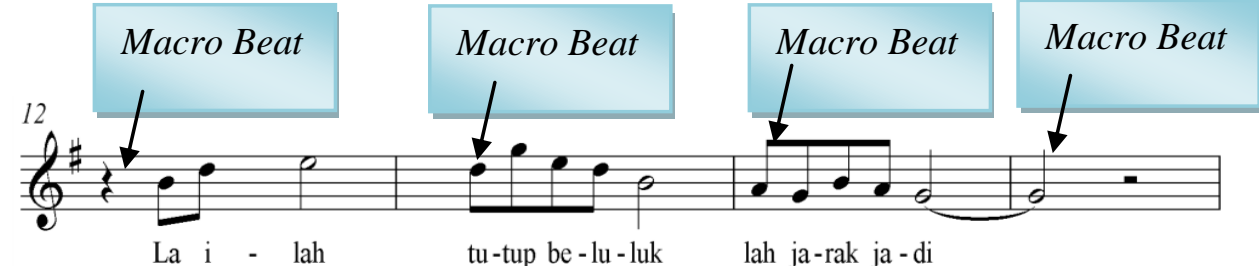

\# Micro Beat bagian A

$\mathbf{a}$

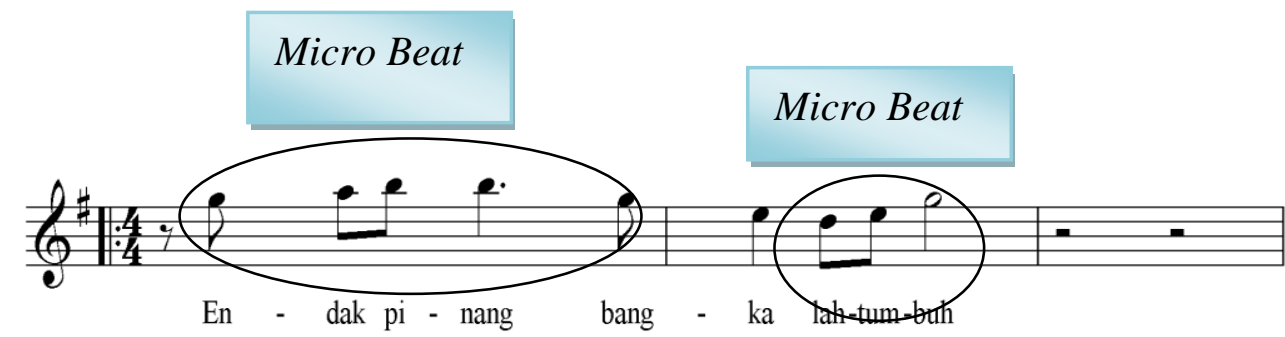

$>\quad \mathbf{a}^{\prime}$

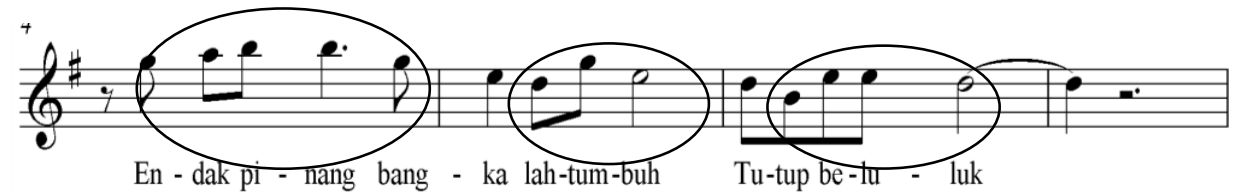

\# $\quad$ Micro Beat bagian B

b

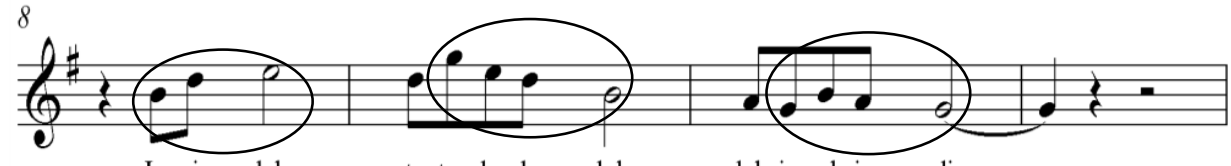

La i - lah tu-tup be-lu - luk lah ja-rak ja - di 
Febrian Tarmizi

$>\mathbf{b}$

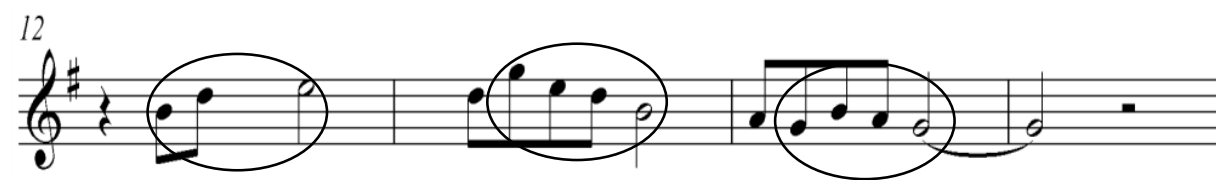

La i - lah tu-tup be-lu-luk lah ja-rak ja-di

* Crusic, Metacrusic dan Anacrusic bagian A

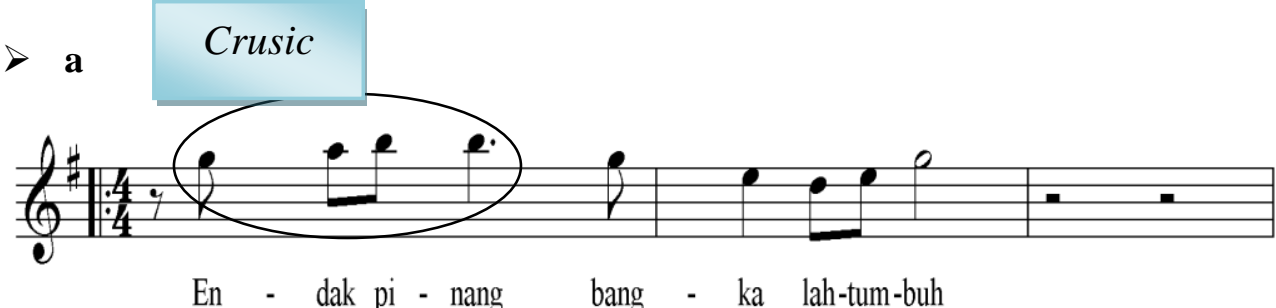

En - dak pi - nang bang - ka lah-tum-buh

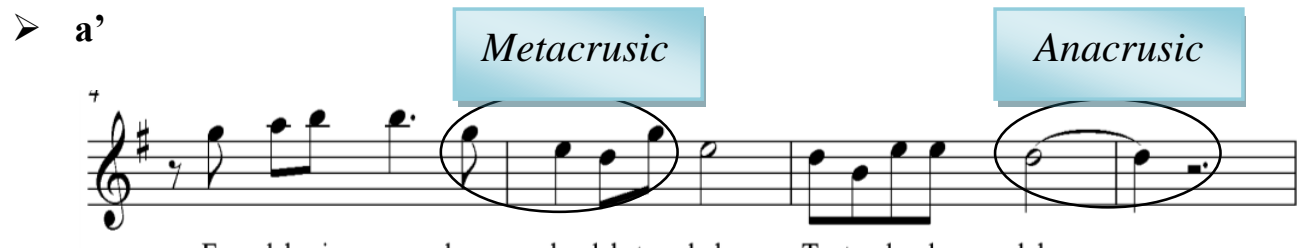

En - dak pi - nang bang - ka lah-tum-buh Tu-tup be-lu - luk

\# Crusic, Metacrusic dan Anacrusic bagian B
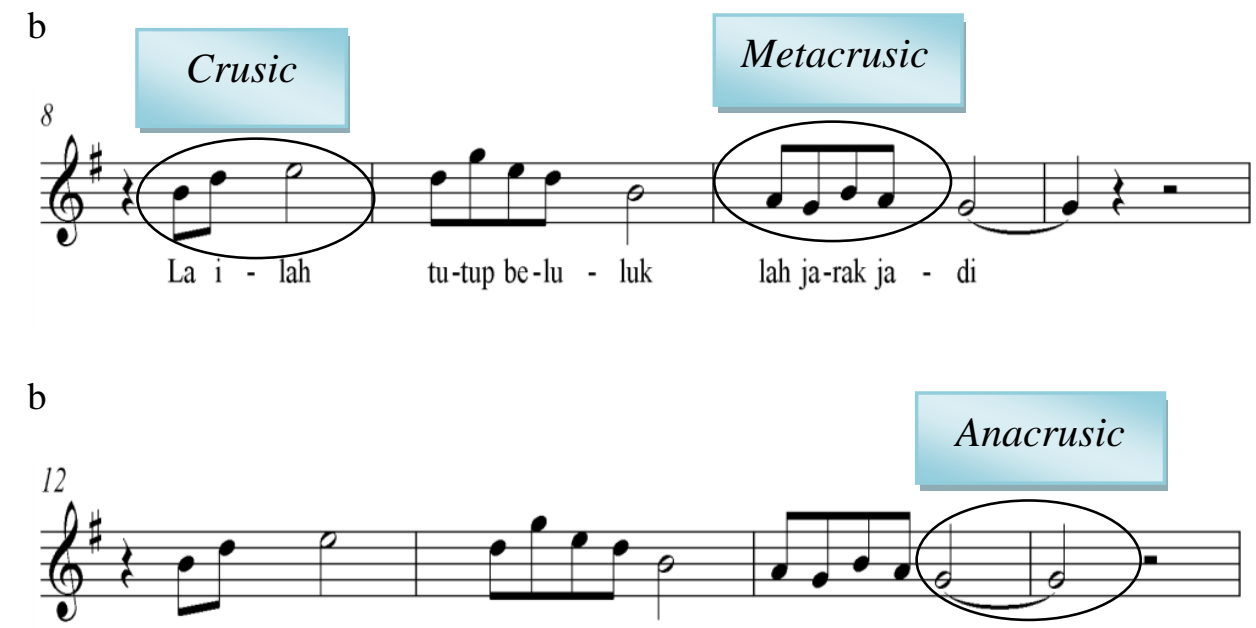

La i - lah tu-tup be-lu-luk lah ja-rak ja-di 
Pola Musik Pengiring Rejung "Khindu di Hati"

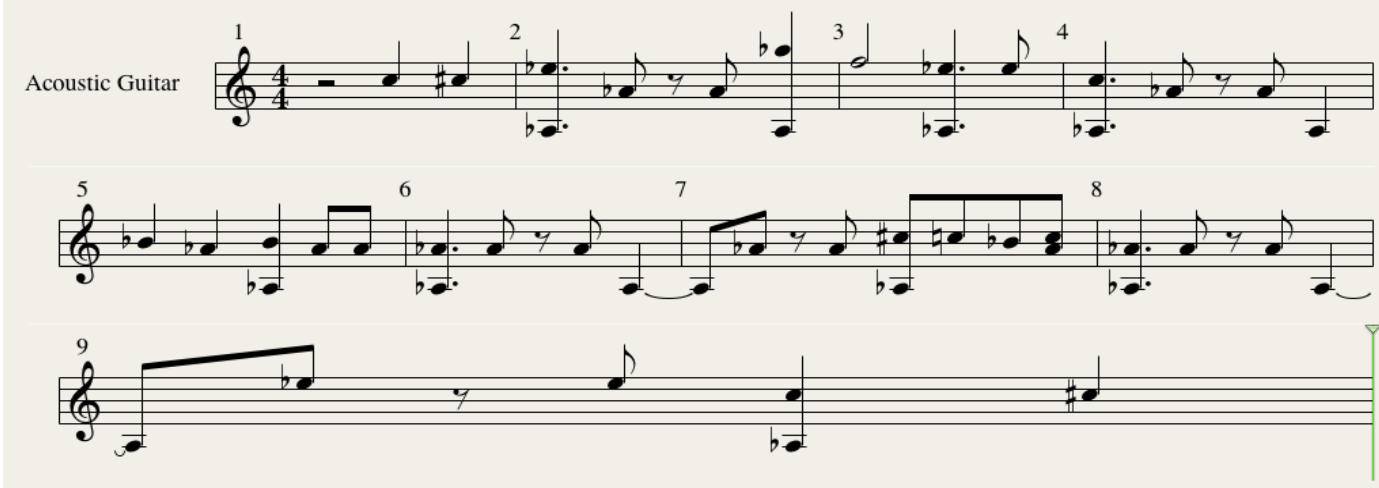

Pola Fartitur Rejung "Khindu di Hati"

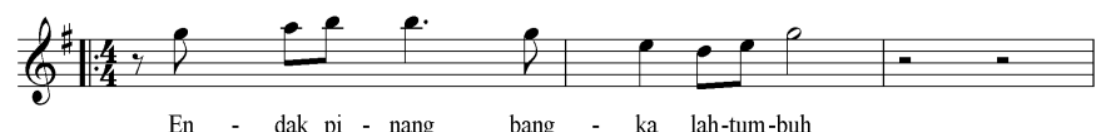

En - dak pi - nang bang - ka lah-tum-buh
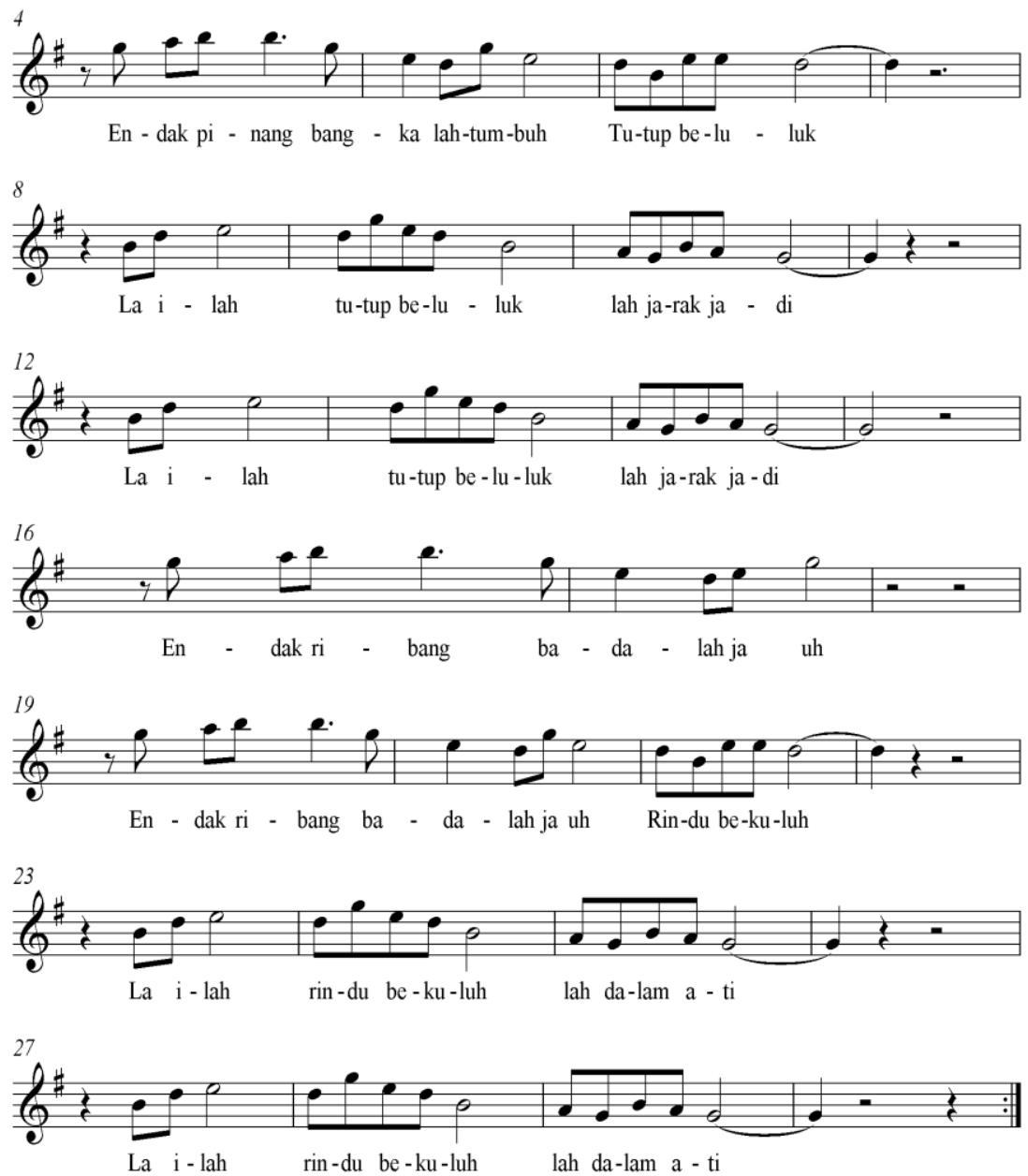


\section{SIMPULAN}

Dari anlisis musik lagu Rejung "Kindu di Hati" daerah Bengkulu Selatan dapat di simpulkan bahwa Rejung "Khindu di Hati" memiliki dua bagian. Bagian pertama disebut $\mathbf{A}$ terdiri dari (a, a') a adalah antecedens atau kalimat tanya sedangkan a' adalah consequens atau kalimat jawab. Bagian kedua disebut dengan B. maksud dari b sama dengan $\mathbf{b}$ adalah Pengulangan atau Repetisi. Birama pada Rejung "Khindu di Hati" adalah 4/4, tekstur pada lagu ini Monopohny dan mempunyai dua bagian lagu yaitu A dan B sepeti yang telah di uraikan di atas tesebut.

\section{SARAN}

Musik lagu Rejung "Kindu di Hati" daerah Bengkulu Selatan hendaknya mendapat perhatian dari Pemerintah, Seniman dan Akademis dengan tujuan eksistensi lagu Rejung "Kindu di Hati" lebih baik lagi dari tahun ke tahun bukan sebaliknya. Untuk peneliti selanjutnya disarankan meneliti kajian Teks pada lagu Rejung "Kindu di Hati" daerah Bengkulu Selatan.

\section{DAFTAR PUSTAKA}

Alwasilah, A Chaedar. 2009. Pokoknya Kualitatif. Dasar-Dasar merancang dan Melakukan Penelitian Kualitatif Jakarta: PT Dunia Pustaka Jaya.

Departemen Pendidikan dan Kebudayaan Pusat Penelitian Sejarah dan Budaya Proyek Penelitian dan Pencatatan Bebudayaan Daerah. 1997/1998. Adat-istiadat Daerah Bengkulu. Bengkulu.

Departemen Pendidikan dan Kebudayaan Kantor Wilayah Propinsi Bengkulu Direktorat Sejarah dan Nilai Tradisional Bagian Proyek Pengkajian dan Pembinaan Nilainilai Budaya Bengkulu. 1995/1996. Adat dan Upacara Perkawinan Daerah Bengkulu. Bengkulu.

Kayam, Umar. 1981. Seni Tradisi Masyarakat. Jakarta: PT. Sinar Harapan.

Koentjaraningrat. 1982. Kebudayaan, Mentalitas dan pengembangan. Jakarta: Gramedia

Merrian, Allan P. 1964. The Anthropology Of Music. Chicago: Northwestern. University Perss.

Moleong, Lexy j. 1986. Metode Penelitian Kualitatif. Jakarta PT. Remaja Rusada.

Tim Penyusun Pusat Pembinaan dan Pengembangan Bahasa. 1995 Kamus Besar Bahasa Indinesia. 